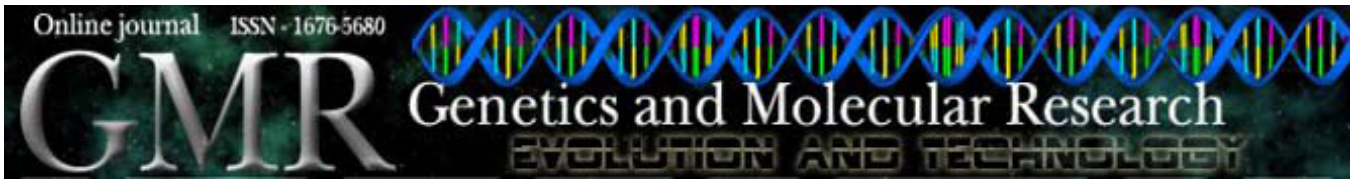

\title{
Additive genetic relationship of longevity with fertility and production traits in Nellore cattle based on bivariate models
}

\author{
M.H. Van Melis ${ }^{1,2}$, H.N. Oliveira ${ }^{3}$, J.P. Eler ${ }^{1}$, J.B.S. Ferraz ${ }^{1}$, J. Casellas ${ }^{3}$ \\ and L. Varona ${ }^{3,4}$ \\ ${ }^{1}$ Grupo de Melhoramento Animal e Biotecnologia, \\ Faculdade de Zootecnia e Engenharia de Alimentos da Universidade de São Paulo, \\ Pirassununga, SP, Brasil \\ ${ }^{2}$ Faculdade de Ciências Agrárias e Veterinárias, Universidade Estadual Paulista, \\ Jaboticabal, SP, Brasil \\ ${ }^{3}$ Area de Genética Animal, IRTA, Lleida, Spain \\ ${ }^{4}$ Departamento de Anatomía, Embriología y Genética Animal, \\ Universidad de Zaragoza, Zaragoza, Spain \\ Corresponding author: J.B.S. Ferraz \\ E-mail: jbferraz@usp.br
}

Genet. Mol. Res. 9 (1): 176-187 (2010)

Received October 9, 2009

Accepted November 18, 2009

Published February 2, 2010

\begin{abstract}
Survival or longevity is an economically important trait in beef cattle. The main inconvenience for its inclusion in selection criteria is delayed recording of phenotypic data and the high computational demand for including survival in proportional hazard models. Thus, identification of a longevity-correlated trait that could be recorded early in life would be very useful for selection purposes. We estimated the genetic relationship of survival with productive and reproductive traits in Nellore cattle, including weaning weight (WW), post-weaning growth (PWG), muscularity (MUSC), scrotal circumference at 18
\end{abstract}


months (SC18), and heifer pregnancy (HP). Survival was measured in discrete time intervals and modeled through a sequential threshold model. Five independent bivariate Bayesian analyses were performed, accounting for cow survival and the five productive and reproductive traits. Posterior mean estimates for heritability (standard deviation in parentheses) were 0.55 (0.01) for WW, 0.25 (0.01) for PWG, $0.23(0.01)$ for MUSC, and $0.48(0.01)$ for SC18. The posterior mean estimates (95\% confidence interval in parentheses) for the genetic correlation with survival were $0.16(0.13-0.19), 0.30(0.25-0.34), 0.31(0.25-$ $0.36), 0.07$ (0.02-0.12), and 0.82 (0.78-0.86) for WW, PWG, MUSC, $\mathrm{SC} 18$, and HP, respectively. Based on the high genetic correlation and heritability (0.54) posterior mean estimates for HP, the expected progeny difference for HP can be used to select bulls for longevity, as well as for post-weaning gain and muscle score.

Key words: Beef cattle; Reproduction; Bos indicus; Growth traits; Bayesian approach; Genetic correlation

\section{INTRODUCTION}

Survival and longevity are economically important traits in beef cattle (Newman et al., 1992; Melton, 1995; Phocas et al., 1998). During the last decades, several statistical methods for survival analyses have been proposed, such as the proportional hazard model (Cox, 1972). This procedure has been broadly implemented in several countries to predict breeding values for longevity (Ducrocq et al., 1988; Ducrocq and Casella, 1996; de Jong et al., 1999). The main disadvantage of selection for longevity is the delayed recording of phenotypic data, which would increase the generation interval (Ducrocq et al., 1988; Vollema and Groen, 1997). Therefore, correlated traits recorded early in lifetime would be very useful for selection purposes. However, multivariate models including survival pose some difficulties because the joint multivariate distribution cannot be described using standard mixed model procedures (González-Recio and Alenda, 2007). Some interesting approaches have been developed within the multivariate frame (Nguti et al., 2005; Tarrés et al., 2006), and Damgaard and Korsgaard (2006) proposed a joint Bayesian analysis of the survival trait with a Gaussian trait using Markov Chain Monte Carlo. Nevertheless, this was a computation-demanding method even for data sets of moderate size (GonzálezRecio and Alenda, 2007).

Survival can also be measured in discrete-time intervals (e.g., number of calvings along lifetime) as described by Prentice and Gloeckler (1978) or Ducrocq (1999). Within this context, longevity records can be analyzed under adapted survival analysis methodologies, such as the sequential threshold model (STM) (Albert and Chib, 2001; González-Recio et al., 2005). Besides, González-Recio and Alenda (2007) proposed the use of STM to analyze one discrete-time survival and one Gaussian trait, simultaneously.

Following this approach, the objective of this research was to study the genetic relationship of longevity, understood as cumulated fertility of cows, with productive and reproductive traits in Nellore cattle, using the sequential threshold model in bivariate analyses. 


\section{MATERIAL AND METHODS}

\section{Data}

Data were obtained from 15 herds owned by Agro-Pecuaria CFM Ltda. and located in the States of São Paulo, Mato Grosso do Sul, and Goiás, in Brazil. This company owns close to 20,000 Nellore cattle and sells about 2000 young bulls per year of 8000 weaned bull calves. For the individuals, weaning weight (WW), post-weaning gain (PWG), muscle score at 18 months (MUSC18), scrotal circumference at 18 months (SC18), and heifer pregnancy (HP) were recorded. Survival (SURV) was defined in this study as the number of calvings per female, 17 calvings being the maximum value. Usually in this population, cows calved every year and SURV was almost equivalent to the age of the cow. Longevity records from cows still alive on December 31, 2006 were considered as censored $(9.8 \%$ of total). Scrotal circumference measurements were taken at the greatest diameter of the scrotum, using a metal tape device, and were carried out at approximately 18 months. Muscle score was determined by a set of experts after visual evaluation of each animal around 18 months of age. Animals with poor muscle content received a score of 1 , and animals with the highest muscle content received a score of 6 . Weaning weight of animals was recorded at around 205 days. Post-weaning gain was calculated as the weight gain of an animal between 205 (weaning) and 550 (yearling) days of age. Finally, Heifer pregnancy was defined as the observation that a heifer conceived and remained pregnant by rectal palpation, when exposed at breeding time. The females were exposed to sires at approximately 14 months of age (between 11 and 16 months). Binary observations, with 0 indicating failure and 1 indicating success, were used for each female.

The dataset included HP and SURV records of Nellore females born between 1994 and 2005 and between 1984 and 2003, respectively. For WW, PWG, MUSC18, and SC18, the dataset included records of animals born between 1984 and 2004.

\section{Cattle management}

A detailed description concerning herd management can be found in Eler et al. (2004). The cows were maintained on pasture, with salt and mineral supplementation $(11 \% \mathrm{Ca}, 6 \% \mathrm{P}, 1 \% \mathrm{Mg}, 4 \% \mathrm{~S}, 16 \% \mathrm{Na}, 0.15 \% \mathrm{Cu}, 0.15 \% \mathrm{Mn}, 0.45 \% \mathrm{Zn}, 0.015 \% \mathrm{I}$, $0.007 \% \mathrm{Co}$, and $0.002 \% \mathrm{Se}$ ). Every year, the mating season began in November and ended in January, lasting 60 days for cows and 90 days for heifers. Artificial insemination and natural service mating were used in lots with one or several sires. The ratio of cows per bull was about $35: 1$. For HP and SURV, the dataset used in this study was based on reproductive performance records for females that were exposed to first breeding beginning at either 2 years of age (1986-1994), or at 14 months of age (1995-2006). Since 1995, heifers that failed to conceive at 14 months were retained until the next breeding season when they were exposed again ( 2 years old). After this age, non-conceiving heifers and cows were culled, meaning that a cow that remained in the herd was fertile (Table 1). All females were evaluated for pregnancy (rectal palpation) approximately 60 days after the end of breeding season. Some culling may have also been performed on the basis of poor progeny performance and health. 


\begin{tabular}{|c|c|c|c|}
\hline Calving number & Number of records & Number of culled cows & $\%$ culled cows \\
\hline 1 & 134,965 & 16,034 & 11.88 \\
\hline 2 & 114,998 & 47,639 & 41.43 \\
\hline 3 & 64,767 & 23,135 & 35.72 \\
\hline 4 & 39,969 & 11,751 & 29.40 \\
\hline 5 & 27,231 & 7,322 & 26.89 \\
\hline 6 & 18,938 & 4,960 & 26.19 \\
\hline 7 & 13,233 & 3,268 & 24.70 \\
\hline 8 & 9,312 & 2,092 & 22.47 \\
\hline 9 & 6,785 & 1,513 & 22.30 \\
\hline 10 & 4,884 & 1,159 & 23.73 \\
\hline 11 & 3,412 & 1,012 & 29.66 \\
\hline 12 & 2,191 & 736 & 33.59 \\
\hline 13 & 1,300 & 556 & 42.77 \\
\hline 14 & 646 & 289 & 44.74 \\
\hline 15 & 298 & 168 & 56.38 \\
\hline 16 & 123 & 84 & 68.29 \\
\hline 17 & 38 & 29 & 76.32 \\
\hline Overall & 441,803 & 117,283 & \\
\hline
\end{tabular}

\section{Statistical model}

The STM described by Albert and Chib (2001) and González-Recio and Alenda (2007) was used to analyze SURV as a categorical trait that occurred in a sequential order. This means that, for an observation to be present at a given stage of the sequence, it must have passed through all previous stages. Suppose that the $j$ th calving is observed for a given cow. The response $y_{\mathrm{i}}$ can take the value $j$ only after levels $1, \ldots, j-1$ are previously reached, and then, either a "success" (survival) or "failure" (culling or death) in level $j$ is observed. Hence, the probability of survive at calving $j$, conditionally on the event that the $(j-1)$ th calving has been reached, is given by:

$$
\operatorname{Pr}\left(\mathrm{y}_{\mathrm{i}}=\mathrm{j} \mid \mathrm{y}_{\mathrm{i}} \geq \mathrm{j}-1, \gamma, \mathbf{X}_{\mathrm{i}} \theta_{\mathrm{i}}\right)=\Phi\left[\mathrm{y}_{\mathrm{j}}-\left(\mathbf{x}_{\mathrm{i}}^{\prime} \theta_{i}\right)\right] \quad \text { (Equation 1) }
$$

where the vector $\gamma=\left(\gamma_{1}, \gamma_{2}, \ldots, \gamma_{\mathrm{j}-1}, \gamma_{\mathrm{j}}\right)$ represents unordered cutpoints and $\mathbf{X}_{\mathrm{i}}^{\prime} \theta_{i}$ represents the explanatory effects of the covariates. This probability function is referred to as the discrete-time hazard function (Prentice and Gloeckler, 1978; Tutz, 1990, 1991). Therefore, a single latent variable can be used to represent the cow's propensity to pass from one category to the next (González-Recio and Alenda, 2007). Corresponding to the $j$ th calving, latent variables $\left\{\omega_{\mathrm{ij}}\right\}$ are defined. We observe $y_{\mathrm{i}}=1$ if $\omega_{\mathrm{i} 1} \leq \gamma_{1}$, and we observe $y_{\mathrm{i}}=2$ if the first latent variable $\omega_{\mathrm{i} 1}>$ $\gamma_{1}$ and the second latent variable $\omega_{\mathrm{i} 2} \leq \gamma_{2}$. In general:

$$
y_{i}= \begin{cases}1 & \text { if } \omega_{i 1} \leq \gamma_{1} \\ 2 & \text { if } \omega_{i 1}>\gamma_{1}, \omega_{i 2} \leq \gamma_{2} \\ 3 & \text { if } \omega_{i 1}>\gamma_{1}, \omega_{i 2}>\gamma_{2}, \omega_{i 3} \leq \gamma_{3} \\ \vdots & \\ \text { so } \text { on }\end{cases}
$$

(Equation 2) 
Thus, associated with the latent variable vector $(\omega)$, we implemented Bayesian bivariate models to analyze the genetic relationship for discrete-time survival (SURV), jointly with Gaussian (WW, PWG, MUSC18, SC18) or threshold (HP) traits. The latent variable representation can be simplified by incorporating the cutpoints $\left\{\gamma_{i}\right\}$ into the mean function and fixing one of the cutpoints, usually $\gamma_{1}=0$.

\section{Gaussian-STM model}

A bivariate model was defined for both latent variable $(\omega)$ for SURV and y for the Gaussian traits (WW, PWG, MUSC18, SC18). The assumed model for the latent variable $(\omega)$ was a repeatability model:

$$
\omega=\gamma+\mathbf{X}_{\omega} \beta_{\omega}+\mathbf{Z}_{\omega} \mathbf{u}_{\omega}+\mathbf{W}_{\omega} \mathbf{p}_{\omega}+\mathbf{e}_{\omega}
$$

(Equation 3)

where for each of the Gaussian traits (y), the model was:

$$
\boldsymbol{y}=X_{g} \beta_{g}+Z_{g} u_{g}+e_{g},
$$

(Equation 4)

where $\beta_{\omega}$ and $\beta_{\mathrm{g}}$ are the vectors of systematic effects for SURV and each of the Gaussian traits, respectively. For SURV, systematic effects consist of a contemporary group (between 83 and 2249 levels) and breeding farm (24 levels). For Gaussian traits, systematic effects included in the model were the contemporary group (see Table 2), dam's age class at calving (see Table 3 ), and age at recording (WW, PWG and MUSC) as linear covariate; $\mathrm{u}_{\omega}$ and $\mathrm{u}_{\mathrm{g}}$ are the vectors of additive genetic effects for SURV and each Gaussian trait, $\mathrm{p}_{\omega}$ is the permanent environment effect for SURV trait and $e_{\omega}$ and $e_{g}$ are the vector of residual effects for SURV and each of Gaussian traits, respectively. Furthermore, $\mathrm{X}_{\omega}, \mathrm{X}_{\mathrm{g}}, \mathrm{Z}_{\omega}, \mathrm{Z}_{\mathrm{g}}$, and $\mathrm{W}_{\omega}$ are known incidence matrices corresponding to systematic, genetic and permanent environment effects.

The following prior distributions were assumed:

$$
\begin{gathered}
p\left(\beta_{\omega}\right) \propto \text { improper uniform } \\
p\left(\beta_{g}\right) \propto \text { improper uniform } \\
\quad p\left(\boldsymbol{e}_{\omega} \mid \boldsymbol{I}\right) \sim N(0, \boldsymbol{I}) \\
p\left(\boldsymbol{e}_{g} \mid \boldsymbol{I}, \sigma_{e_{g}}^{2}\right) \sim N\left(0, I \sigma_{e_{g}}^{2}\right)
\end{gathered}
$$


where

$$
\mathrm{G}=\left[\begin{array}{cc}
\sigma_{\mathrm{u}_{\omega \mathrm{g}}}^{2} & \sigma_{\mathrm{u}_{\omega \mathrm{g}}} \\
\sigma_{\mathrm{u}_{\omega \mathrm{g}}} & \sigma_{\mathrm{u}_{\mathrm{g}}}^{2}
\end{array}\right]
$$

is the (co)variance matrix for additive genetic effect, and $\mathrm{A}$ is the numerator relationship matrix.

The prior distribution for the permanent environment effects was:

$$
p\left(\mathbf{p}_{\omega} \mid \sigma_{p_{\omega}}^{2}\right) \sim N\left(0, \mathbf{I} \sigma_{p_{\omega}}^{2}\right)
$$

Prior distributions for variance components $\left(\mathrm{G}, \sigma_{p_{\omega}}^{2}\right.$ and $\left.\sigma_{e_{g}}^{2}\right)$ were uniform priors.

Table 2. Summary statistics of the dataset for weaning weight (WW), postweaning gain (PWG), muscle score

\begin{tabular}{|c|c|c|c|c|c|}
\hline \multirow[t]{2}{*}{ Item } & \multicolumn{5}{|c|}{ Trait } \\
\hline & WW & PWG & MUSC & $\mathrm{SC} 18$ & HP \\
\hline Number of records & 96,401 & 67,624 & 59,927 & 51,030 & 28,912 \\
\hline Number of contemporary groups & 2,249 & 1,997 & 1,725 & 1,456 & 83 \\
\hline Mean of the trait & 183.4 & 115.16 & 3.75 & 27.5 & - \\
\hline Range of measure & 61.0 to 317.0 & -78.2 to 294.5 & 1.00 to 6.00 & 10.4 to 41.4 & - \\
\hline Mean of the age (days) & 199.51 & - & & - & - \\
\hline Range of age (days) & 140 to 270 & - & 450 to 650 & - & - \\
\hline Number of successful records & - & - & - & - & 4,650 \\
\hline$\%$ Success & - & - & - & - & 16.10 \\
\hline
\end{tabular}
(MUSC), scrotal circumference at 18 months (SC18), and heifer pregnancy (HP) traits.

Table 3. Dam's age class at calving (DAC), age of dam, and number of dams per class per weaning weight

\begin{tabular}{|c|c|c|c|c|}
\hline \multirow[t]{2}{*}{$\mathrm{DAC}$} & \multirow[t]{2}{*}{ Age (months) } & \multicolumn{3}{|c|}{ Number of dams } \\
\hline & & WW & PWG & MUSC18 \\
\hline 1 & $<27$ & 187 & 65 & 66 \\
\hline 2 & 28 to 36 & 18,941 & 13,171 & 11,152 \\
\hline 3 & 37 to 48 & 16,105 & 11,077 & 10,089 \\
\hline 4 & 49 to 72 & 17,775 & 12,177 & 11,027 \\
\hline 5 & 73 to 120 & 30,675 & 22,025 & 19,357 \\
\hline 6 & 121 to 144 & 7,254 & 5,358 & 4,684 \\
\hline 7 & 145 to 180 & 4,690 & 3,251 & 3,063 \\
\hline 8 & $>180$ & 774 & 500 & 489 \\
\hline Total & - & 96,401 & 67,624 & 59,927 \\
\hline
\end{tabular}
(WW), post-weaning gain (PWG) and muscle (MUSC18) traits.

\section{Threshold-STM model}

As before, a bivariate model was used to analyze the latent variable for SURV ( $\omega$ and another latent variable $(\delta)$ for HP. 
The model of analysis for SURV was the same as before:

$$
\boldsymbol{\omega}=\gamma+\mathbf{X}_{\omega} \boldsymbol{\beta}_{\omega}+\mathbf{Z}_{\omega} \mathbf{u}_{\omega}+\mathbf{W}_{\omega} \mathbf{p}_{\omega}+\mathbf{e}_{\omega}
$$

(Equation 11)

and for HP, the model was:

$$
\boldsymbol{\delta}=\mathbf{X}_{\delta} \boldsymbol{\beta}_{\delta}+\mathbf{Z}_{\delta} \mathbf{u}_{\delta}+\mathbf{e}_{\delta}
$$

where $\delta$ was the liability that defined the categories of response in HP; $\beta_{\delta}$ was a vector of systematic effects (contemporary groups (CG) - 82 levels - and age at the beginning of breeding season as a linear covariate); $\mathrm{u}_{\delta}$ was a vector of additive genetic effects; $\mathrm{e}_{\delta}$ was a vector of residual effects, and $\mathrm{X}_{\delta}, \mathrm{Z}_{\delta}$ are known incidence matrices.

The following prior distributions were assumed:

$$
\begin{gathered}
p\left(\beta_{\delta}\right) \propto \text { improper uniform } \\
p\left(\mathbf{e}_{\delta}\right) \propto N(0, \mathbf{I})
\end{gathered}
$$

(Equation 13)

(Equation 14)

As before, prior distribution for breeding values was multivariate Gaussian, and prior distributions for variance components were uniform priors.

Contemporary groups were defined by the combinations of farm, year of birth, and breeding farm of the cow (farm where females were exposed to the bulls) for SURV; farm, year of birth, weaning and post-weaning management groups, and breeding farm for HP; farm, year of birth, and weaning and post-weaning management groups for each animal for PWG, MUSC18 and SC18, and farm, year of birth, and weaning management groups for WW. Only $\mathrm{CG}$ with at least five records were considered. Moreover, data from animals with unknown parents and belonging to a $\mathrm{CG}$ with no variability for categorical traits were eliminated to avoid extreme category problems (Moreno et al., 1997). With the same objective, CG with all females censored were also discarded.

\section{Gibbs sampler}

Posterior distributions of all the parameters in the model were estimated using a Gibbs sampling algorithm (Gelfand and Smith, 1990) with a data augmentation step (Tanner and Wong, 1987; Sorensen et al., 1995). The latent variables ( $\omega$ and $\delta$ ) were augmented from truncated Gaussian distributions with appropriate arguments. The conditional distributions for systematic effects, breeding values and permanent environmental effects were univariate Gaussian distributions. The conditional distribution for $\mathrm{G}$ was an inverse Wishart distribution, and the conditional distributions for $\sigma_{p_{\omega}}^{2}$ and $\sigma_{e_{g}}^{2}$ were inverse chi-square distributions. The analyses were run as a single chain of 125,000 cycles. All samples were stored for computing posterior means, medians, modes, $\mathrm{SD}$, and credible regions. 


\section{RESULTS AND DISCUSSION}

\section{Analysis of convergence of the Gibbs sampler}

Visual inspections of the trace plots from the outputs of the Gibbs sampler were used to access the number of iterations and the required length of burn-in. For instance, the convergence for the genetic parameters in the analysis between SURV and WW was shown in the trace plots presented in Figure 1. The behavior of the trace plots was similar for other trait combinations. The required length of the burn-in period was always less than 5000 iterations. However, a conservative strategy was adopted and the first 5000 iterations were discarded for each analysis.
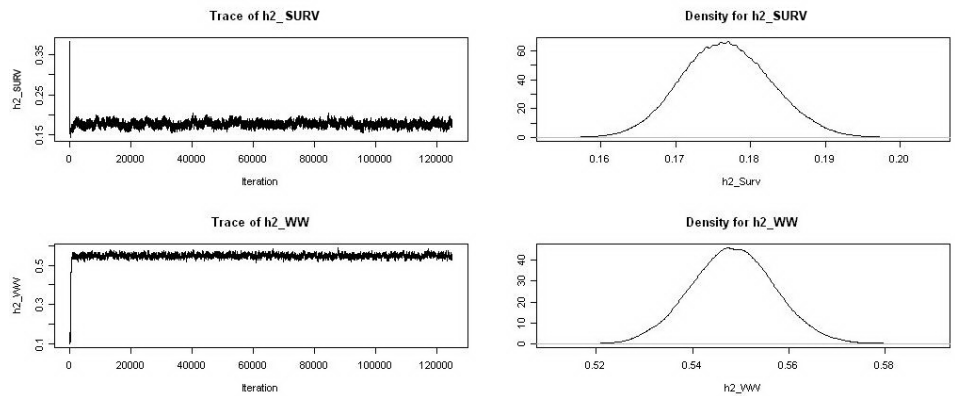

Trace of rg between SURV and WW
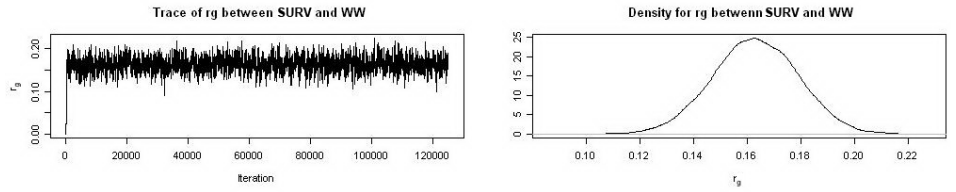

Figure 1. Trace plots and posterior density of heritability estimate for survival (SURV) and weaning weight (WW) and genetic correlation $\left(\mathrm{r}_{\mathrm{g}}\right)$ in Nellore cattle.

\section{Heritabilities}

Posterior means, medians, modes, and SD, as well as the highest posterior density intervals at $95 \%$ for the heritabilities are presented in Table 4.

Table 4. Posterior means \pm standard deviations (SD), modes, medians, and $95 \%$ highest posterior density (HPD) intervals of heritability coefficients in multivariate analysis for survival (SURV) with weaning weight (WW), post-weaning gain (PWG), muscle score (MUSC), scrotal circumference at 18 months (SC18), or heifer pregnancy (HP) in Nellore cattle.

\begin{tabular}{|c|c|c|c|c|}
\hline Heritability & Mean \pm SD & Mode & Median & $95 \%$ HPD \\
\hline \multicolumn{5}{|l|}{ SURV } \\
\hline with WW & $0.18 \pm 0.01$ & 0.18 & 0.18 & 0.17 to 0.19 \\
\hline with PWG & $0.18 \pm 0.01$ & 0.18 & 0.18 & 0.17 to 0.19 \\
\hline with MUSC & $0.17 \pm 0.01$ & 0.17 & 0.17 & 0.16 to 0.18 \\
\hline with SC18 & $0.17 \pm 0.01$ & 0.17 & 0.17 & 0.16 to 0.18 \\
\hline with HP & $0.20 \pm 0.01$ & 0.20 & 0.20 & 0.19 to 0.21 \\
\hline WW & $0.55 \pm 0.01$ & 0.55 & 0.55 & 0.53 to 0.57 \\
\hline PWG & $0.25 \pm 0.01$ & 0.25 & 0.25 & 0.22 to 0.26 \\
\hline MUSC & $0.23 \pm 0.01$ & 0.23 & 0.23 & 0.21 to 0.26 \\
\hline SC18 & $0.42 \pm 0.01$ & 0.42 & 0.42 & 0.39 to 0.44 \\
\hline HP & $0.54 \pm 0.03$ & 0.54 & 0.54 & 0.48 to 0.60 \\
\hline
\end{tabular}


Posterior means \pm posterior SD for heritability of SURV ranged from $0.17 \pm 0.01$ to 0.20 \pm 0.01 for SURV. Previous studies with beef cattle reported heritability estimates closer to the one obtained here. For instance, Silva et al. (2006) and Van Melis et al. (2007) analyzed stayability at 6 years old in Nellore cattle under a threshold model, and they obtained heritability estimates of $0.24 \pm 0.03$ and $0.22 \pm 0.03$, respectively. Furthermore, Caraviello et al. (2005) estimated a heritability for longevity of 0.18 , using a Weibull proportional hazard model in Jersey cattle. Moreover, Martínez et al. (2004) estimated genetic parameters for length of productive life (with six opportunity groups) and found heritability estimates between 0.05 and 0.15 in Hereford cattle. Finally, González-Recio and Alenda (2007) using the same sequential threshold model that we applied here found a heritability estimate equal to $0.11 \pm 0.01$ for survival in dairy cattle.

Posterior mean estimate of heritability for WW $(0.55 \pm 0.01)$ was greater than other studies in the literature, such as Horimoto et al. (2007) in Nellore cattle $(0.28 \pm 0.04)$ and Speidel et al. (2007) in the Asturiana breed in Spain (0.45 \pm 0.04$)$. However, it must be considered that the statistical model considered here does not include maternal effects, and a substantial upward estimate is expected. For PWG, posterior mean estimate of heritability $(0.25 \pm$ $0.01)$ is within the range of estimates found by Eriksson et al. (2002; 0.22 to 0.40$)$ in Swedish beef cattle and Van Melis et al. (2003; 0.27) in Nellore cattle, applying the R method (Reverter et al., 1994). Estimated heritability of MUSC18 $(0.23 \pm 0.01)$ was similar to values reported in other studies. For instance, Van Melis et al. (2003) presented an estimate of heritability of 0.22 , using the R method, and Cardoso et al. (2004) found an estimated heritability of 0.26 , using REML. However, the heritability estimated in this study was higher than the value reported by Forni et al. (2007) in a Nellore population with REML $(0.12 \pm 0.01)$. Posterior mean of heritability for SC18 $(0.42 \pm 0.01)$ indicates the existence of significant genetic variance for this trait, similar to values found in the literature. In Bos taurus populations, Bourdon and Brinks (1986) estimated the heritability of age-adjusted scrotal circumference in Herefords of $0.46 \pm 0.06$, and Martínez-Velázquez et al. (2003) reported values of $0.41 \pm 0.04$ for 9 pure and 3 composite populations. Moreover, Smith et al. (1989) obtained an average estimate of $0.40 \pm 0.09$ for several breeds, and, in Nellore Cattle, Silva et al. (2006) estimated a heritability of $0.46 \pm 0.02$. Finally, the heritability estimate of $0.54 \pm 0.03$ obtained in this study for HP confirms the existence of significant genetic variance for this trait as well. Similar heritability values in Nellore cattle $(0.57 \pm 0.11,0.61 \pm 0.10$, and $0.58 \pm 0.13)$ were reported by Eler et al. $(2002,2004)$ and Pereira et al. (2007). However, in Bos taurus populations, Evans et al. (1999) and Doyle et al. (2000) found lower heritability estimates for Hereford and Angus breeds (0.14 \pm 0.18 , and $0.21 \pm 0.12$, respectively). On average, the Nellore breed (Bos indicus) shows puberty at a later age, and the genetic variability of $\mathrm{HP}$ at 14 months seems to be much higher, due to the strong relationship of the trait with puberty (Eler et al., 2004).

Estimates of variance due to permanent environmental effect of animals as a proportion of total variance for SURV trait ranged from $0.38 \pm 0.01$ to $0.39 \pm 0.01$. Thus, the ability to survive from calving to the next one is determined mostly by accumulated environmental effects over lifetime than by genetic effects.

\section{Genetic correlations}

Genetic correlation estimates between SURV and productive and reproductive traits are presented in Table 5. Moderate and favorable genetic correlation estimates between SURV 
and PWG, and SURV and MUSC were found in the present study $(0.30 \pm 0.03$, and $0.31 \pm$ 0.03 , respectively). PWG and MUSC are currently used as selection criteria in the Nellore population. Thus, slight genetic response is expected on SURV with the current selection scheme. To our knowledge, no previous genetic correlation estimates between SURV and PWG or MUSC exist in the literature. Only Silva et al. (2006) reported an estimate of genetic correlation between stayability at 6 years and post-weaning weight (at around of 18 months) of $0.15 \pm 0.00$, in Nellore cattle.

Table 5. Posterior means \pm standard deviations (SD), modes, medians, and 95\% highest posterior density (HPD) intervals of genetic correlation coefficients in multivariate analysis for survival (SURV) with weaning weight (WW), post-weaning gain (PWG), muscle score (MUSC), scrotal circumference at 18 months (SC18), or heifer pregnancy (HP) in Nellore cattle.

\begin{tabular}{lcccc}
\hline Genetic correlation & Mean \pm SD & Mode & Median & $95 \%$ HPD \\
\hline SURV $\times$ WW & $0.16 \pm 0.02$ & 0.16 & 0.16 & 0.13 to 0.19 \\
SURV $\times$ PWG & $0.30 \pm 0.03$ & 0.29 & 0.29 & 0.25 to 0.34 \\
SURV $\times$ MUSC & $0.31 \pm 0.03$ & 0.31 & 0.31 & 0.25 to 0.36 \\
SURV $\times$ SC18 & $0.07 \pm 0.03$ & 0.07 & 0.07 & 0.02 to 0.12 \\
SURV $\times$ HP & $0.82 \pm 0.02$ & 0.82 & 0.82 & 0.78 to 0.86 \\
\hline
\end{tabular}

Low positive genetic correlation estimates were found in the present study between SURV and WW, and between SURV and SC18 (0.16 \pm 0.02 and $0.07 \pm 0.01$, respectively). This suggests that a selection criterion based on these traits may not modify the ability of females to remain in the herd for a long period by producing one calf per year. In agreement with the genetic correlation estimate found in this study between stayability at 6 years and SC18, Silva et al. (2006) reported an estimate of genetic correlation of $0.07 \pm 0.03$ in Nellore cattle.

The estimate of genetic correlation between SURV and HP found in this study ( 0.82 $\pm 0.03)$ is as very high and favorable, indicating that using HP as a selection criterion would satisfactorily improve also SURV, i.e., the ability of females to remain in the herd by producing one calf per year during lifetime. In the same sense, previous genetic correlation estimate between HP and stayability at 6 years was reported to be $0.64 \pm 0.07$ (Van Melis MH, Oliveira HN, Eler JP, Rosa GJM, et al., unpublished results).

\section{FINAL REMARKS}

The high heritability estimate for HP and the high genetic correlation between HP and SURV obtained in the present study confirm that the expected progeny difference for HP can be used to select bulls for the production of precocious, fertile and long-lived daughters. Measuring HP is evidently much easier and more straightforward than measuring SC18, that is, the indicator reproductive trait used routinely as selection criteria, and thus a selection scheme based solely on HP would be tempting. However, the modest genetic correlation between HP and SC18 traits $(0.27 \pm 0.10$ and $0.29 \pm 0.05)$ reported by Eler et al. (2006) and Van Melis et al. (2008) indicates that the indirect genetic gain on SC18 would not be satisfactory using only $\mathrm{HP}$ as a selection criterion.

Genetic analyses between one discrete-time survival and either one linear or one threshold trait were carried out using either bivariate linear-sequential threshold models or bivariate threshold-sequential threshold models, respectively. Genetic correlations of SURV 
with productive and reproductive traits of interest were estimated with field data and no twostep approach was needed as by Tarrés et al. (2006). The method used in this paper and presented by González-Recio and Alenda (2007) may handle large data sets, and an animal model may be implemented for evaluation of survival considering time-dependent covariates (farm where females were exposed to the bulls). The ease of implementation in huge data sets enables the estimation of genetic correlations with other productive and reproductive traits of interest that can be used as early predictors of survival. Although the method proposed by Damgaard and Korsgaard (2006) is exact and attractive, its practical implementation with huge data sets is unfeasible.

The model presented here assumes that the latent variable for SURV remains constant over the lifetime of cows. Further research must be done considering different genetic determinism at different stages of life. Thus, a multivariate animal model can be implemented for the survival latent variable. Another possibility is to consider a longitudinal model for the latent variable, and it can be described as a random regression model for the latent variable as reported by Averill et al. (2006).

\section{ACKNOWLEDGMENTS}

Publication supported by FAPESP.

\section{REFERENCES}

Albert JH and Chib S (2001). Sequential ordinal modeling with applications to survival data. Biometrics 57: 829-836.

Averill T, Rekaya R and Weigel K (2006). Random regression models for male and female fertility evaluation using longitudinal binary data. J. Dairy Sci. 89: 3681-3689.

Bourdon RM and Brinks JS (1986). Scrotal circumference in yearling Hereford bulls: adjustment factors, heritabilities and genetic, environmental and phenotypic relationships with growth traits. J. Anim. Sci. 62: 958-967.

Caraviello DZ, Weigel KA, Shook GE and Ruegg PL (2005). Assessment of the impact of somatic cell count on functional longevity in Holstein and Jersey cattle using survival analysis methodology. J. Dairy Sci. 88: 804-811.

Cardoso FF, Cardellino RA and Campos LT (2004). (Co) variance components and genetic parameters of post-weaning traits in Angus cattle. R. Bras. Zootec. 33: 313-319.

Cox DR (1972). Regression models and life-tables. J. R. Stat. Soc. Ser. B Stat. Methodol. 34: 187-220.

Damgaard LH and Korsgaard IR (2006). A bivariate quantitative genetic model for a linear Gaussian trait and a survival trait. Genet. Sel. Evol. 38: 45-64.

de Jong G, Vollema AR, van der Beek S and Harbers A (1999). Breeding value for functional longevity in the Netherlands. Interbull Bull. 21: 68-72.

Doyle SP, Golden BL, Green RD and Brinks JS (2000). Additive genetic parameter estimates for heifer pregnancy and subsequent reproduction in Angus females. J. Anim. Sci. 78: 2091-2098.

Ducrocq V (1999). Extension of survival analysis models to discrete measures of longevity. Interbull Bull. 21: 41-48.

Ducrocq V and Casella G (1996). A Bayesian analysis of mixed survival models. Genet. Sel. Evol. 28: 505-529.

Ducrocq V, Quaas RL and Pollak EJ (1988). Length of productive life of dairy cows. 2. Variance component estimation and sire evaluation. J. Dairy Sci. 71: 3071-3079.

Eler JP, Silva JA, Ferraz JB, Dias F, et al. (2002). Genetic evaluation of the probability of pregnancy at 14 months for Nellore heifers. J. Anim. Sci. 80: 951-954.

Eler JP, Silva JA, Evans JL, Ferraz JB, et al. (2004). Additive genetic relationships between heifer pregnancy and scrotal circumference in Nellore cattle. J. Anim. Sci. 82: 2519-2527.

Eler JP, Ferraz JB, Balieiro JC, Mattos EC, et al. (2006). Genetic correlation between heifer pregnancy and scrotal circumference measured at 15 and 18 months of age in Nellore cattle. Genet. Mol. Res. 5: 569-580.

Eriksson S, Näsholm A, Johansson K and Philipsson J (2002). Genetic analysis of post-weaning gain of Swedish beef cattle recorded under field conditions and at station performance testing. Livest. Prod. Sci. 76: 91-101. 
Evans JL, Golden BL, Bourdon RM and Long KL (1999). Additive genetic relationships between heifer pregnancy and scrotal circumference in Hereford cattle. J. Anim. Sci. 77: 2621-2628.

Forni S, Federici JF and Albuquerque LG (2007). Genetic trends in Nelore cattle selected for visual scores of conformation, precocity and musculature at weaning. R. Bras. Zootec. 36: 572-577.

Gelfand AE and Smith AFM (1990). Sampling-based approaches to calculating marginal densities. J. Am. Stat. Assoc. 85: 398-409.

González-Recio O and Alenda R (2007). Genetic relationship of discrete-time survival with fertility and production in dairy cattle using bivariate models. Genet. Sel. Evol. 39: 391-404.

González-Recio O, Chang YM, Gianola D and Weigel KA (2005). Number of inseminations to conception in Holstein cows using censored records and time-dependent covariates. J. Dairy Sci. 88: 3655-3662.

Horimoto AR, Ferraz JB, Balieiro JC and Eler JP (2007). Phenotypic and genetic correlations for body structure scores (frame) with productive traits and index for CEIP classification in Nellore beef cattle. Genet. Mol. Res. 6: 188-196.

Martínez GE, Koch RM, Cundiff LV, Gregory KE, et al. (2004). Genetic parameters for six measures of length of productive life and three measures of lifetime production by 6 yr after first calving for Hereford cows. J. Anim. Sci. 82: 1912-1918.

Martínez-Velázquez G, Gregory KE, Bennett GL and Van Vleck LD (2003). Genetic relationships between scrotal circumference and female reproductive traits. J. Anim. Sci. 81: 395-401.

Melton BE (1995). Conception to Consumption: The Economics of Genetic Improvement. In: Proceedings of the Beef Improvement Federation, 27, Research Symposium and Annual Meeting, Sheridan, 40-47.

Moreno C, Sorensen D, García-Cortés LA, Varona L, et al. (1997). On biased inferences about variance components in the binary threshold model. Genet. Sel. Evol. 29: 145-160.

Newman S, Morris CA, Baker RL and Nicoll GB (1992). Genetic improvement of beef cattle in New Zealand: Breeding objectives. Livest. Prod. Sci. 32: 111-130.

Nguti R, Burzykowski T, Rowlands J, Renard D, et al. (2005). Joint modelling of repeated measurements and event time: application to performance traits and survival of lambs bred in sub-humid tropics. Genet. Sel. Evol. 37: 175-197.

Pereira E, Oliveira HN, Eler JP, Silva JA II V, et al. (2007). Comparison among three approaches for evaluation of sexual precocity in Nellore cattle. Animal 1: 411-418.

Phocas F, Bloch C, Chapelle P, Bécherel F, et al. (1998). Developing a breeding objective for a French purebred beef cattle selection programme. Livest. Prod. Sci. 57: 49-65.

Prentice RL and Gloeckler LA (1978). Regression analysis of grouped survival data with application to breast cancer data. Biometrics 34: 57-67.

Reverter A, Golden BL, Bourdon RM and Brinks JS (1994). Method R variance components procedure: application on the simple breeding value model. J. Anim. Sci. 72: 2247-2253.

Silva JA II V, Formigoni IB, Eler JP and Ferraz JBS (2006). Genetic relationship among stayability, scrotal circumference and post-weaning weight in Nelore cattle. Livest. Sci. 99: 51-59.

Smith BA, Brinks JS and Richardson GV (1989). Estimation of genetic parameters among reproductive and growth traits in yearling heifers. J. Anim. Sci. 67: 2886-2891.

Sorensen DA, Andersen S, Gianola D and Korsgaard I (1995). Bayesian inference in threshold models using Gibbs sampling. Genet. Sel. Evol. 27: 229-249.

Speidel SE, Enns RM and Garrick DJ (2007). Weaning weight inheritance in environments classified by maternal body weight change. J. Anim. Sci. 85: 610-617.

Tanner MA and Wong WH (1987). The calculation of posterior distributions by data augmentation. J. Am. Stat. Assoc. 82: 528-540.

Tarrés J, Piedrafita J and Ducrocq V (2006). Validation of an approximate approach to compute genetic correlations between longevity and linear traits. Genet. Sel. Evol. 38: 65-83.

Tutz G (1990). Sequential item response models with an ordered response. Br. J. Math. Stat. Psychol. 43: 39-55.

Tutz G (1991). Sequential models in categorical regression. Comput. Stat. Data Anal. 11: 275-295.

Van Melis MH, Eler JP, Silva JA II V and Ferraz JBS (2003). Estimate of genetic parameters in beef cattle using restricted maximun likelihood and method Â. Rev. Bras. Zootec. 32: 1624-1632.

Van Melis MH, Eler JP, Oliveira HN, Rosa GJ, et al. (2007). Study of stayability in Nellore cows using a threshold model. J. Anim. Sci. 85: 1780-1786.

Vollema AR and Groen AF (1997). Genetic correlations between longevity and conformation traits in an upgrading dairy cattle population. J. Dairy Sci. 80: 3006-3014. 